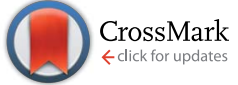

Cite this: RSC Adv., 2016, 6, 64977

\title{
Effect of subcritical water on homogeneous catalysis of used cooking oil hydrolysis $\uparrow$
}

\author{
Ong Lu Ki, ${ }^{a}$ Tran Nguyen Phuong Lan, ${ }^{b}$ Soetaredjo Felycia Edi, ${ }^{c}$ Ismadji Suryadi ${ }^{\star c}$ \\ and Ju Yi-Hsu*a
}

The effect of temperature and pressure on the batch hydrolysis of used cooking oil in fatty acids(autocatalytic system), dilute acid- (pH 5.0), and dilute $\mathrm{Cu}$-catalyzed systems $(500 \mathrm{mg} \mathrm{CuSO} 4 \mathrm{per} \mathrm{kg}$ solution) was studied. The reaction was carried out using a fixed water/acylglycerides molar ratio of $30: 1$ under various temperatures $\left(200-250^{\circ} \mathrm{C}\right.$ ) and initial pressures $(1.96-4.90 \mathrm{MPa})$ for $2 \mathrm{~h}$. Experimental data were processed statistically using ANOVA and the Spearman correlation method aside of conventional data interpretation. The $\mathrm{Cu}$-catalyzed system was superior to the other systems. Temperature had greater effect on oil hydrolysis than initial pressure. The use of $\mathrm{CO}_{2}$ as the pressurizing gas altered fatty acid production and $\mathrm{Cu}$ soap formation particularly by oil dilution that also accompanied by a slight acidification of the aqueous phase. The water ionization constant was the most influencing property for fatty acid production and Cu soap formation.

Received 7th June 2016 Accepted 2nd July 2016

DOI: $10.1039 / c 6 r a 14807 g$

www.rsc.org/advances manipulated. High temperature of SCW also benefits oil hydrolysis, which was identified as an endothermic reaction.,

In industrial scale, oil hydrolysis is carried out with or without a presence of catalyst. The non-catalytic approach, such as in Colgate-Emery process, utilizes SCW properties to induce selfcatalysis mechanism of available FAs beside improving oil-water miscibility. ${ }^{\mathbf{1 , 6}}$ Industrial catalysis process for oil hydrolysis reaction may employ acid, base, transition metal, or enzyme., ${ }^{2,7}$ Among all catalyst, only inorganic type can be involved in subcritical water state due to thermal degradation of enzyme in very hot water. Since the use of base as catalyst generates sludge, soap by-product, and hard wastewater in the down-stream of the process, Bronsted or Lewis acid catalyst such as mineral acid or transition metal is commonly used as industrial catalyst for oil hydrolysis. ${ }^{8}$

Global scarcity of water, especially in the arid and semi-arid area is one of the top issues that the world faces now and is expected to get worse in the future. This issue promotes wastewater reuse and recycling to satisfy water demand for domestics, industrials, recreational, and agricultural purposes. Among of wastewater types, heavy metal laden wastewaters take a special position due to its toxicity to human and environment. ${ }^{9}$ Heavy metals in wastewater need to be separated before wastewater can be recycled for reuse. Many techniques are known today to treat heavy metals in wastewater, such as membrane filtration, chemical precipitation, ion exchange, adsorption, and electrochemical deposition. ${ }^{\mathbf{1 0}}$ However, all these methods are generally expensive in terms of capital cost, material fabrication, and material regeneration, which overall hinder its application for treating large volume of industrial wastewater. ${ }^{10,11}$

Heavy metals in wastewater come from numerous sources, such as metal plating facilities, battery manufacturing

\footnotetext{
${ }^{a}$ Department of Chemical Engineering, National Taiwan University of Science and Technology, 43, Keelung Rd., Sec. 4, Taipei 10607, Taiwan. E-mail: yhju@mail. ntust.edu.tw; Fax: +88622737 6644; Tel: +886227376612

${ }^{b}$ Department of Mechanical Engineering, Can Tho University, 3-2 Street, Can Tho City, Vietnam

${ }^{c}$ Department of Chemical Engineering, Widya Mandala Surabaya Catholic University, Kalijudan 37, Surabaya, Indonesia. E-mail: suryadiismadji@yahoo.com

$\dagger$ Electronic supplementary information (ESI) available. See DOI: 10.1039/c6ra14807g
} 
industries, electronic industries, mining, and metallurgical industries. ${ }^{\mathbf{1 0 , 1 2 , 1 3}}$ Copper $(\mathrm{Cu})$ is a heavy metal that often appears in wastewater, particularly in printed circuit board wastewater. ${ }^{\mathbf{1 4}}$ With a fast growth in the production of communication devices lately, generation of large amount of $\mathrm{Cu}$-containing wastewater is concomitantly increasing with printed circuit board demands. A recent study revealed that $\mathrm{Cu}$-containing wastewater can be used to hydrolyze waste cooking oil, which may solve this issue from the wastewater reuse viewpoint. ${ }^{15}$ From the same study, water at subcritical state was mentioned to affect catalysis mechanism of acidified and non-catalytic system. However, the effect of SCW was only hypothesized from the FA production rate at elevated temperature without any statistical assessment. Moreover, deeper and holistic discussions on the relationship between operating parameters, SCW properties, and the catalysis mechanism involved are not found in published studies on the same subject. ${ }^{\mathbf{1 6 , 1 7}}$

In this study, the effect of temperature and initial pressure towards the formation of FA and copper removal was analyzed statistically in this study to further understand the role of operating parameters in the SCW properties adjustment in the oil hydrolysis reaction. Correlation between water properties including negative logarithmic value of ionic product $\left(-\log K_{\mathrm{w}}\right)$, static dielectric constant $(\varepsilon)$, dynamic viscosity $(\mu)$, and density $(\rho)$ at respective temperature and actual pressure to FA yield and copper removal percentage were evaluated. The use of $\mathrm{CO}_{2}$ was also compared as the substitute of $\mathrm{N}_{2}$ for pressurizing the reaction system. Thorough discussion of the effect of SCW properties towards the reaction catalysis was also incorporated. acetate (99.9\%) were obtained from Merck (USA) and Echo Chemical (Taiwan), respectively. Industrial grade hexane was obtained from a local chemical supplier. A mixture of 37 fatty acid methyl esters (FAMEs) obtained from Supelco (Bellefonte, PA, USA) was used to identify fatty acid profile of used cooking oil.

\subsection{Used cooking oil hydrolysis}

Used cooking oil and $\mathrm{CuSO}_{4}$ solution with a concentration of $500 \mathrm{mg} \mathrm{CuSO}_{4}$ per $\mathrm{kg}$ solution was introduced into a custommade batch reactor. A constant molar ratio of triacylglycerides to water at 1:30 was always used. The reactor apparatus comprised a $200 \mathrm{~mL}$ glass chamber, 316-grade stainless steel autoclave body, a K-type thermocouple, a PID temperature controller, a pressure gauge, a magnetic stirrer, and an external electric heater (Fig. S1 $\dagger$ ). After closed the reactor tightly, nitrogen was introduced to purge out oxygen. For the evaluation of pressure effect, nitrogen pressure in the reactor headspace was kept at 1.96-4.90 $\mathrm{MPa}$. The reactor was then heated to the desired temperature $\left(200{ }^{\circ} \mathrm{C}, 225^{\circ} \mathrm{C}\right.$ or $\left.250{ }^{\circ} \mathrm{C}\right)$ for $2 \mathrm{~h}$. Final pressure at the corresponding temperature was recorded to determine the values of SCW properties according to Alexandrov, et al. ${ }^{18}$ The reaction system was then cooled down to 50-60 ${ }^{\circ} \mathrm{C}$. Glycerol was removed by washing the oil twice with warm water in a separation funnel. The top layer (oil product) was weighed and analyzed for its acid value (AV) and Cu content. The FA yield percentage was calculated by using the following equations:

$$
\text { FA yield }(\%)=\frac{\mathrm{AV}_{\text {oil product }}(\mathrm{mg} \mathrm{KOH} \mathrm{per} \mathrm{g} \mathrm{oil}) \times m_{\text {oil product }}(\mathrm{g})-\mathrm{AV}_{\text {oil feed }}(\mathrm{mg} \mathrm{KOH} \mathrm{per} \mathrm{g} \mathrm{oil}) \times m_{\text {oil feed }}(\mathrm{g})}{(\mathrm{SV}-\mathrm{AV})_{\text {oil feed }}(\mathrm{mg} \mathrm{KOH} \text { per } \mathrm{g} \text { oil }) \times m_{\text {oil feed }}(\mathrm{g})} \times 100 \%
$$

\section{Experimental}

\subsection{Chemicals}

Used cooking oil was collected from a local restaurant in Taipei, Taiwan. The oil was stored in an amber glass bottle and used without further pretreatment. Reagent grade chemicals were used: $\mathrm{KOH}$ (85\%, Across Organics, USA), anhydrous $\mathrm{CuSO}_{4}\left(97 \%\right.$, Shimakyu, Japan), anhydrous $\mathrm{MgSO}_{4}$ ( $\geq 99.5 \%$, Showa Denko, Japan), HCl (37\% purity, Across Organics, USA), $\mathrm{H}_{2} \mathrm{SO}_{4}$ (95-97\%, Scharlau Chemical, Spain), $\mathrm{NaCl}$ ( $\geq 99.5 \%$, Showa Denko, Japan), ethanol (95\%, Echo Chemical, Taiwan), and oxalic acid dihydrate ( $\geq 99 \%$, Kokusan Chemical Co. Ltd., Japan). Phenolphthalein (Sigma Aldrich, USA) in ethanol was used as titration indicator. $\mathrm{CuSO}_{4}$ stock solution was made from its anhydrous salt with a concentration of $25000 \mathrm{mg} \mathrm{kg}{ }^{-1}$. Analytical reagent grade $\mathrm{HNO}_{3}(90 \%$, May and Baker, UK) was used for copper ion extraction of fatty acids products. A mixed standard solution (solution IV, $1000 \mathrm{mg} \mathrm{L}^{-1}$, Merck Chemicals, USA) was used to obtain $\mathrm{Cu}$ calibration curve in the inductively coupled plasma (ICP) measurement. HPLC grade methanol (99.5\%) and ethyl
Acid catalytic and FA autocatalytic systems were evaluated also by changing the copper solution with $\mathrm{H}_{2} \mathrm{SO}_{4}$-acidified water (pH 5.0) and deionized water, respectively. In the other type of experiments, $\mathrm{CO}_{2}$ was used as the pressurizing gas. Experiments involving different catalyst systems and gas types were done at the studied temperature and pressure range with the same acylglycerides/water molar ratio $(1: 30)$.

\subsection{Oil analysis}

AV was analyzed titrimetrically according to ASTM D1980-87 method and calculated from the amount of $\mathrm{KOH}$ used.

$$
\mathrm{AV}(\mathrm{mg} \mathrm{KOH} \text { per g oil })=\frac{V_{\mathrm{KOH}}(\mathrm{mL}) \times C_{\mathrm{KOH}}(\mathrm{N}) \times 56.1}{\text { wt. of sample }(\mathrm{g})}
$$

SV was determined by titration method (ASTM D5558-95) as the basis of maximum obtainable fatty acid in the used cooking oil. SV was calculated by using eqn (3). 


$$
\begin{aligned}
& \mathrm{SV}(\text { mg KOH per g oil })= \\
& \qquad \frac{V_{\mathrm{HCl}} \text { of blank }- \text { sample }(\mathrm{mL}) \times N_{\mathrm{HCl}}(\mathrm{N}) \times 56.1}{\text { wt. of sample }(\mathrm{g})}
\end{aligned}
$$

Ester value (EV) and average molecular weight of the used cooking oil $\left(\mathrm{MW}_{\mathrm{av}}\right)$ as pure triacylglycerides can be calculated from eqn (4) and (5), respectively.

$$
\begin{aligned}
\mathrm{EV}(\mathrm{mg} \mathrm{KOH} \text { per } \mathrm{g} \text { oil })= & \mathrm{SV}(\mathrm{mg} \mathrm{KOH} \text { per g oil }) \\
& -\mathrm{AV}(\mathrm{mg} \mathrm{KOH} \text { per } \mathrm{g} \text { oil })
\end{aligned}
$$

was determined by extraction using a previously studied method with slight modification. ${ }^{25}$ Oil sample $(5 \mathrm{~g})$ was mixed with $10 \%(\mathrm{v} / \mathrm{v}) \mathrm{HNO}_{3}(20 \mathrm{~mL})$ and held at $60{ }^{\circ} \mathrm{C}$ for $4 \mathrm{~h}$ under magnetic stirring $(500 \mathrm{rpm})$. After extraction, the mixture was left to separate into oil and water layers and cooled in a refrigerator to solidify the oil layer. Aqueous part was taken after filtration using a $5 \mu \mathrm{m}$ filter paper (Advantec Grade No. 2) and analyzed suing ICP. Copper removal percentage was expressed as the number of $\mathrm{Cu}^{2+}$ transferred into the oil phase to the total $\mathrm{Cu}^{2+}$ introduced into the reaction system as shown in eqn (6).

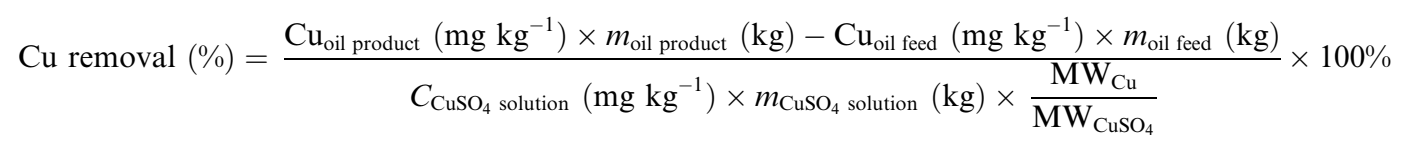

$$
\mathrm{MW}_{\mathrm{av}}=\frac{1000 \times 56.1 \times 3}{\mathrm{EV}_{\text {oil feed }}(\mathrm{mg} \mathrm{KOH} \text { per g oil })}
$$

Reaction behavior of oil feedstock is often dictated by its fatty acids composition that determines its oxidation stability, solubility, and acidity (FA dissociation) according to the unsaturated part and alkyl chain length. ${ }^{19}$ Fatty acids composition of used cooking oil was determined in the form of methyl esters by using gas chromatography (GC-2010, Shimadzu, Japan) equipped with a Rtx-2330 column (10\% cyanopropylphenyl-90\% biscyanopropyl polysiloxane; $30 \mathrm{~m} \times$ $0.25 \mathrm{~mm}$ I.D. $\times 0.2 \mu \mathrm{m})$. The detail of GC operation condition was described elsewhere. ${ }^{20}$ Prior to the GC analysis, $200 \mathrm{mg}$ oil sample was saponified and transesterified using $5 \mathrm{~mL}$ of $0.5 \mathrm{~N}$ $\mathrm{KOH}$ in methanol at $65{ }^{\circ} \mathrm{C}$ for $15 \mathrm{~min}$ and then underwent acidification and esterification by reaction with $15 \mathrm{~mL}$ of methanolic $5 \mathrm{wt} \% \mathrm{H}_{2} \mathrm{SO}_{4}$ at $65{ }^{\circ} \mathrm{C}$ for $1 \mathrm{~h}$. After that, the esters were separated and purified from the methanolic phase by means of hexane dilution (50 mL) and washing with $5 \mathrm{wt} \%$ $\mathrm{NaCl}$ solution $(3 \times 25 \mathrm{~mL})$. Hexane was evaporated under vacuum and esters were further dried by $\mathrm{N}_{2}$ purging. Prior to injection, esters were dissolved in $10 \mathrm{~mL}$ of ethyl acetate and dried by passing the solution over anhydrous $\mathrm{MgSO}_{4}$ in a syringe coupled with a PVDF membrane $(0.22 \mu \mathrm{m})$. The result (Table $\mathrm{S} 1 \dagger$ ) showed that used cooking oil mainly comprised linoleic acid, palmitic acid, and oleic acid, and a small amount of palmitoleic acid and linolenic acid. This could indicate that the used cooking oil was soybean oil, which mainly composed of linoleic acid, oleic acid, palmitic acid, and stearic acid. ${ }^{21,22} \mathrm{~A}$ high spike of palmitic acid and lower stearic acid in the used cooking oil in contrast with refined soybean oil might come from the fatty acid interchange during deep-frying of chicken meat and other foods. ${ }^{23}$ Other remarkable point is its lower content of unsaturated fatty acids than the original soybean oil, which was the result of oxidation during frying process. ${ }^{24}$

In $\mathrm{Cu}$-catalyzed reaction system, $\mathrm{Cu}$ was extracted out from the water to the oil phase. The amount of $\mathrm{Cu}$ inside the oil phase

\subsection{Statistical analysis}

Statistical analysis of all data obtained in this study was carried out using Minitab 17 software. The significance of the effect of employing different catalyst systems, gas types, temperature level, and additional pressure on FA yield was compared using analysis of variance (ANOVA) with interaction term up to second order. The ANOVA test on the influence of gas type, temperature, and initial pressure towards $\mathrm{Cu}$ removal percentage in $\mathrm{Cu}$ catalyzed system was also performed. Spearman correlation analysis was used to evaluate the impact of SCW properties on each pressurized catalyzed system. Categorical variables of catalyst systems and gas types were encoded to ordinal variable for correlation test purpose. $\mathrm{N}_{2}$ and $\mathrm{CO}_{2}$ were labeled as gas 1 and 2 , while the code for autocatalytic, $\mathrm{Cu}$-catalytic, and acidcatalytic systems were system 1, 2, and 3, respectively. Insignificance effect of a term was stated by null hypothesis, which was failed to be rejected if the $p$-value of corresponding term is larger than significance level $(\alpha)$ of 0.05 .

\section{Results and discussion}

\subsection{Effects of experimental parameters on hydrolysis of used cooking oil}

Operating parameters of a process determine the product yield, thus the efficacy of the process. In this study, ANOVA test was employed to evaluate the effect of operating parameters collectively besides conventionally plotting experimental data in certain groups. The collective effect of catalyst system, type of pressurizing gas, temperature, and initial pressure on FA yield is illustrated in Fig. 1, where all experimental data were drawn according to the catalyst system and gas type in Fig. S2. $\dagger$ It is clear that catalyst system had more impact on FA yield than the other parameters. The selection of catalyst can only be explained as a unique criterion in process optimization. In Fig. S2, $\dagger$ this uniqueness is shown as different trend of FA yield with respect to the manipulation of temperature and pressure in each system. Higher FA yield of $\mathrm{Cu}$-catalyzed system than that in the other systems at the same $\mathrm{pH}$ underlines that $\mathrm{Cu}$ in 


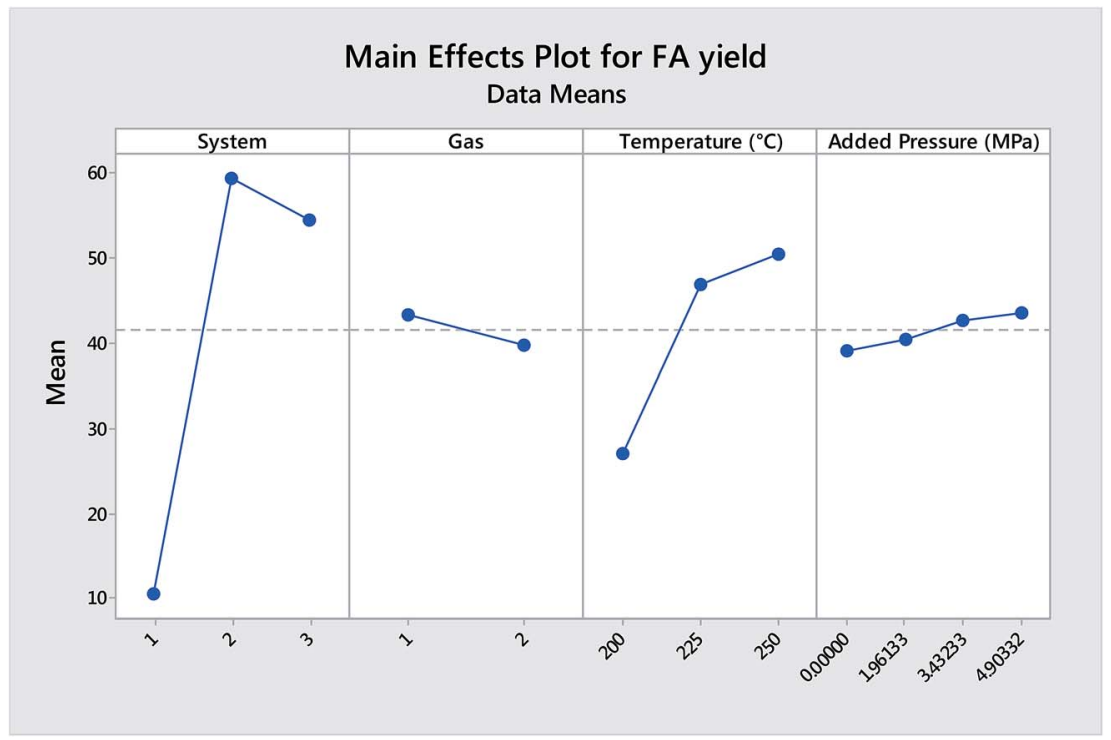

Fig. 1 Main effects plot of catalytic system, gas type, temperature and added pressure with respect to FA yield.

wastewater might be a potential catalyst in oil hydrolysis reaction.

Following catalyst system, temperature took the second place in increasing FA yield, whereas the influence of initial pressure and gas type were relatively minor. Detailed results of ANOVA test (Table $\mathrm{S} 2 \dagger$ ) also shows similar rank of effect on all parameters, which can be seen by the order of magnitude of sum of square error (SS) or mean of square error (MS) term on the mean value of FA yield for each parameter. Higher significance of the effect of temperature than initial pressure using subcritical or supercritical water was observed too in several publications. ${ }^{26-28}$ Although the extent of effective pressure for increasing FA yield differed from one to another, it can be clearly understood that the role of pressure was mainly to retain water in liquid phase, while temperature has abilities to accelerate reaction kinetics in addition to affecting vapor-liquid equilibrium (VLE). Based on that logic, the lesser effect of pressure in this study may be explained by the excessive water/ acylglycerides molar ratio used $(30: 1)$. This result was in agreement with the data depicted in Fig. S2, $\uparrow$ which showed relatively flatter slope of FA yield improvement for the increase of additional pressure in comparison with the ones that describe the raise of temperature.

Substitution of $\mathrm{N}_{2}$ by $\mathrm{CO}_{2}$ has relatively low effect since the solubility of $\mathrm{CO}_{2}$ in water, which was expected to induce $\mathrm{H}_{2} \mathrm{CO}_{3}$ catalyst, is low at the studied temperature. ${ }^{29}$ On the contrary, $\mathrm{CO}_{2}$ is more likely to dissolve in oil than in water that caused a slight decrease of FA yield regardless of catalyst system by means of limiting reactant concentration dilution..$^{30}$ This was also observed by the absence of bubbles in the aqueous phase and foam of bubbles on the oil layer when the after-reaction products were carefully transferred into separation funnel as shown in Fig. S3. $\dagger$ It is also worth to note that the dilution effect of $\mathrm{CO}_{2}$ was different in each catalyst system (Fig. S2 $\dagger$ ). While $\mathrm{CO}_{2}$ only lowered down FA yield without changing the trend of enhancement in acid- and $\mathrm{Cu}$ catalyzed systems, $\mathrm{CO}_{2}$ dramatically altered the shape of surface plot of autocatalytic system. Severe consequence of oil dilution in relatively weak catalysis system is depicted in Fig. S2(B), † where FA yield was suppressed with the increase of $\mathrm{CO}_{2}$ pressure.

ANOVA test on interactions between parameters indicates that combination of catalyst system and temperature is the most effective combination in affecting FA yield (Fig. 2 and Table S2 $\dagger$ ). This is generally true since catalyst and thermal energy input are critical for activation of any reactions. In all catalyst systems, interaction effect of gas type and additional pressure is meaningful particularly related to oil dilution effect by $\mathrm{CO}_{2}$. This problem is also inseparable in the explanation of the significance of catalyst system-added pressure interaction term besides the influence of pressure on SCW properties. The remaining interaction terms generated small variance with respect to the overall mean of FA yield, but their significance is legitimate since the characteristics of main effects were involved in the interaction term too. The insignificance of temperature and pressure interaction is reflected by the parallel lines of mean FA yield in Fig. 2 that increased with increasing temperature, but remained relatively constant under various additional pressures. This again verifies greater effect of temperature to enhance reaction kinetic and the liquid water amount was sufficient in all temperature and pressure ranges studied.

Although the interaction between catalyst system and gas type appeared to be quite weak, further evaluation on this interaction can give deeper insight on the utilization of $\mathrm{CO}_{2}$ with respect to each catalyst system. Fig. $\mathrm{S} 2 \uparrow$ indicates that the effect of $\mathrm{CO}_{2}$ depends on catalyst system. Systems with relatively strong catalysis power, such as the acid- and $\mathrm{Cu}$-catalyzed system, were affected slightly by the increase in temperature and additional $\mathrm{CO}_{2}$ pressure (ca. $5 \%$ reduction of FA yield at $250{ }^{\circ} \mathrm{C}$ and 4.90 $\mathrm{MPa} \mathrm{CO}_{2}$ ). Autocatalysis by FA was too weak to counteract the effect of $\mathrm{CO}_{2}$ dilution since less catalyst was produced from partial FA deprotonation in water. At lower temperature $\left(200^{\circ} \mathrm{C}\right)$ and high added pressure (4.90 $\mathrm{MPa})$, where $\mathrm{CO}_{2}$ solubility in water was considerably high (Fig. S4; $\uparrow$ calculated using the 


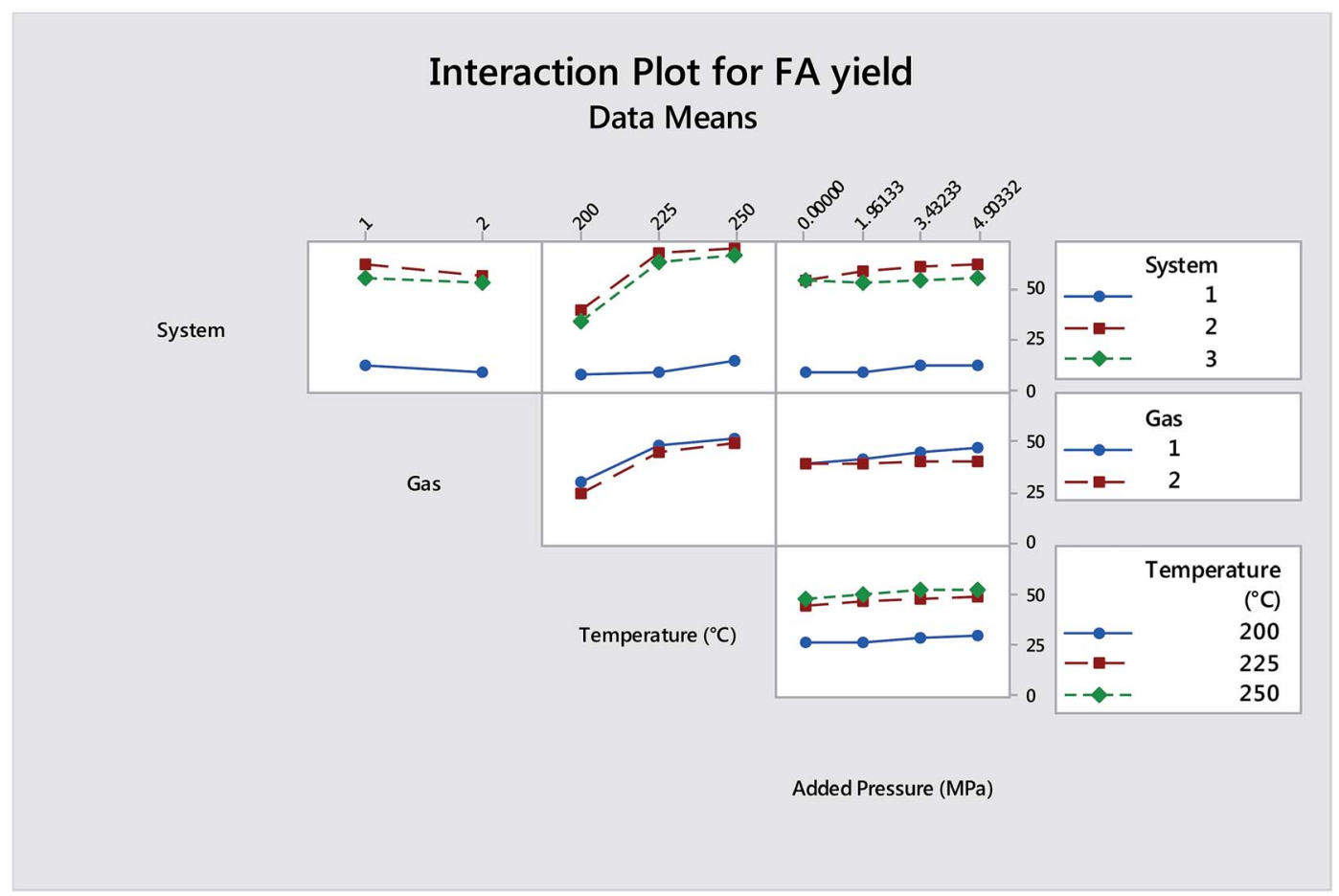

Fig. 2 Plot of interaction between catalyst system, gas type, temperature and added pressure towards of FA yield.

model from Duan and Zhang ${ }^{31}$ ), dilution in the oil phase and inhibition of $\mathrm{Cu}$ soap formation by acidic $\mathrm{H}_{2} \mathrm{CO}_{3}$ in aqueous phase became more prominent. This caused a marked decrease in FA yield with more added $\mathrm{CO}_{2}$ compared with the $\mathrm{N}_{2}$-pressured catalyst system under the same conditions.

\subsection{Effects of experimental parameters on Cu removal percentage}

$\mathrm{Cu}$ removal is determined by equilibrium ion exchange reaction between free $\mathrm{Cu}^{2+}$ and formed fatty acid that produced hydrophobic $\mathrm{Cu}$ soap. ${ }^{15}$ Therefore, the extent of experimental parameters should be also evaluated in the same way as for FA yield. The main and interactional effects of temperature, additional pressure, and gas type on $\mathrm{Cu}$ removal percentage in $\mathrm{Cu}-$ catalyzed system are shown in Fig. 3 and 4, respectively. ANOVA test results for $\mathrm{Cu}$ removal affecting parameters are given in Table S3. $\dagger$

Fig. 3 indicates that temperature and additional pressure enhanced $\mathrm{Cu}$ soap formation, while substitution of $\mathrm{N}_{2}$ by $\mathrm{CO}_{2}$ lowered it. From ANOVA test results, those three parameters

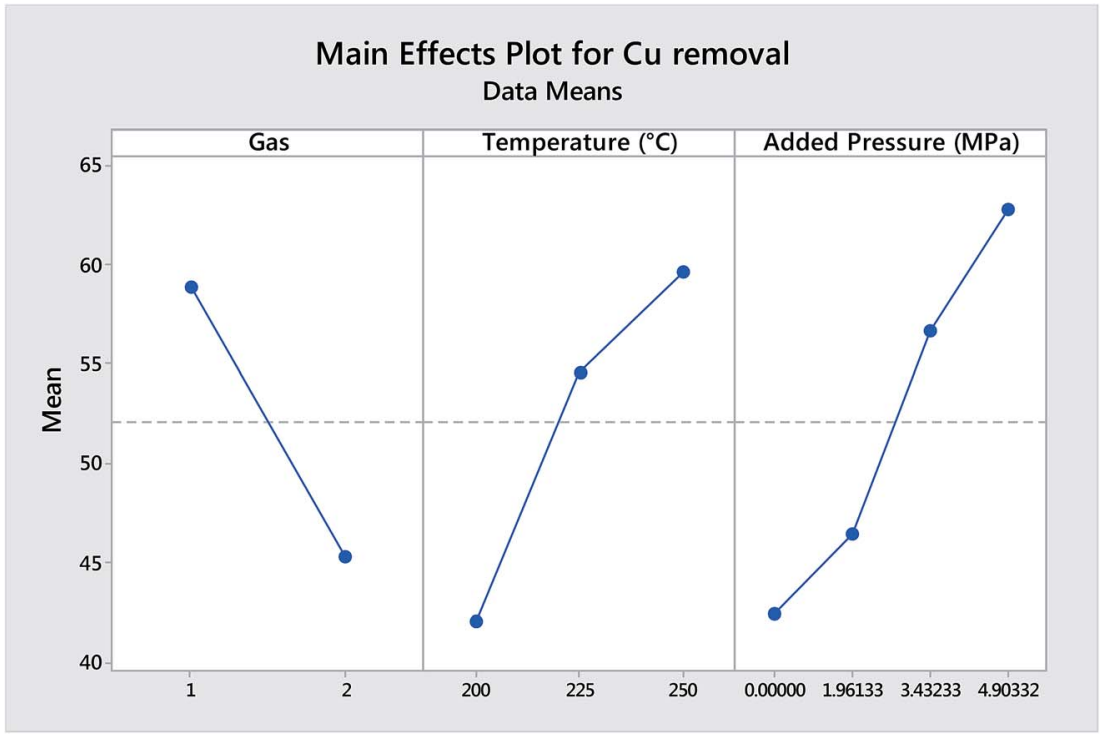

Fig. 3 Main effects plot of gas type, temperature, and added pressure towards Cu removal percentage. 


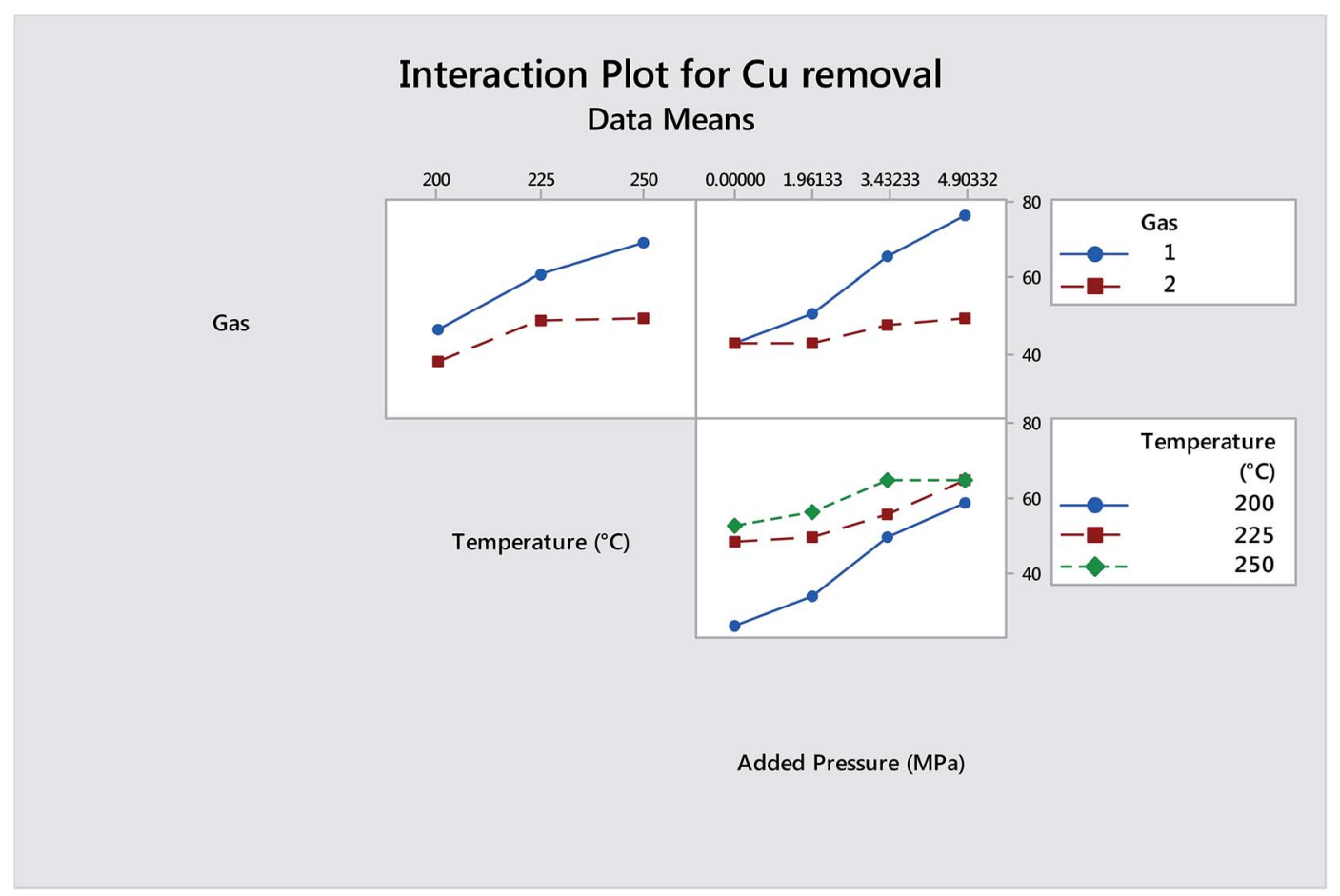

Fig. 4 Interaction effects plot of gas type, temperature, and added pressure towards Cu removal percentage.

demonstrated significant effects on $\mathrm{Cu}$ removal with additional pressure as the most influencing term. These facts suggest that SCW properties strongly affect the formation of $\mathrm{Cu}$ soap. In addition to SCW properties, $\mathrm{Cu}$ soap formation was also controlled by the amount of water in the liquid form that specified good mixing profile between oil and water phase..$^{15}$ In this case, pressure controls the amounts of liquid water by restraining water evaporation under high temperature, explaining its slightly stronger effect than temperature. This control on evaporation may be inadequate under certain operating condition if the additional pressure could not produce final pressure higher than saturation steam pressure as shown at additional pressure of $1.96 \mathrm{MPa}$ in Fig. 3.

A thorough observation on the $3 \mathrm{D}$ plot of $\mathrm{Cu}$ removal percentage (Fig. S5 $\dagger$ ) revealed that substitution of gas type had also altered the effect of added pressure with respect to $\mathrm{Cu}$ removal. The reduction of $\mathrm{Cu}$ removal in the case of gas type substitution can be explained by the presence of $\mathrm{H}_{2} \mathrm{CO}_{3}$ from $\mathrm{CO}_{2}$ solubilization in water. Carbonic acid itself may deprotonate to produce free proton that finally caused inhibition of $\mathrm{Cu}$ soap formation in the aqueous phase. ${ }^{15}$ This also explains the significance of gas type and added pressure interaction in ANOVA test (Table S3 $\dagger$ ). Nevertheless, FAs dilution by supercritical $\mathrm{CO}_{2}$ that limited diffusion of FAs into the water phase was still the main reason for the inhibition of $\mathrm{Cu}$ soap formation since $\mathrm{CO}_{2}$ solubility in the water phase was considerably low.

Parallel arrangement of the lines of responses for interaction of gas type-temperature and temperature-added pressure (Fig. 4) resulted in insignificant interpretation of those terms in Table S2. $\dagger$ Insignificant interaction between gas type and temperature underlines that gas type did not mainly influence the reaction behavior of $\mathrm{Cu}$ soap formation in the aqueous phase. As depicted in Fig. 4, gas type did not significantly change the trend of increasing $\mathrm{Cu}$ removal with increasing temperature regardless of the gas type used, which can be translated as the supremacy of SCW properties over the negative effect of carbonic acid deprotonation as the main controlling factor in $\mathrm{Cu}$ soap formation. This insignificance was not related to the gas solubility since even a small amount of dissolved $\mathrm{CO}_{2}$ can decrease the amount of $\mathrm{Cu}$ removed. Approximately similar $\mathrm{Cu}$ concentration in similar excessive water environment can theoretically explain the insignificant interaction between temperature and added pressure in influencing $\mathrm{Cu}$ soap formation.

\subsection{Correlation between SCW properties, FA yield, and $\mathrm{Cu}$ removal percentage}

SCW properties have been acknowledged as the reasons for utilization of SCW in various organic reactions and processes. ${ }^{3,32}$ Although deemed as physical terms, those properties may affect chemical reaction, especially on the generation of acid-base catalyst and miscibility of aqueous-organic phases. In this study, the effect of SCW properties were measured statistically by correlation constant to observe fluctuation of measurable production parameters (i.e., FA yield and $\mathrm{Cu}$ removal) with respect to SCW properties. Non-linear Spearman correlation was employed to anticipate non-linear fluctuations of SCW properties by the changes of temperature and added pressure. Correlation coefficients of SCW properties towards FA 
Table 1 Spearman correlation index and its bracketed $p$-value between subcritical water properties and FA yield in each catalytic system and gas type

\begin{tabular}{llllll}
\hline System & Gas & $\varepsilon$ & $-\log \left(K_{\mathrm{w}}\right)$ & $\rho$ & $\mu$ \\
\hline FA autocatalytic & $\mathrm{N}_{2}$ & -0.531 & -0.930 & -0.531 & -0.531 \\
& & $(0.075)$ & $(0.000)$ & $(0.075)$ & $(0.075)$ \\
Cu-catalyzed & & -0.622 & -0.986 & -0.622 & -0.622 \\
& & $(0.031)$ & $(0.000)$ & $(0.031)$ & $(0.031)$ \\
Acid-catalyzed & & -0.604 & -0.947 & -0.604 & -0.604 \\
& & $(0.038)$ & $(0.000)$ & $(0.038)$ & $(0.038)$ \\
FA autocatalytic & $\mathrm{CO}_{2}$ & -0.790 & -0.979 & -0.790 & -0.790 \\
& & $(0.002)$ & $(0.000)$ & $(0.002)$ & $(0.002)$ \\
Cu-catalyzed & & -0.671 & -0.986 & -0.671 & -0.671 \\
& & $(0.017)$ & $(0.000)$ & $(0.017)$ & $(0.017)$ \\
Acid-catalyzed & & -0.865 & -0.897 & -0.865 & -0.865 \\
& & $(0.000)$ & $(0.000)$ & $(0.000)$ & $(0.000)$ \\
& & & & &
\end{tabular}

Table 2 Spearman correlation factor of subcritical water propertiesCu removal percentage with $p$-value in parentheses

\begin{tabular}{lllll}
\hline Gas & $\varepsilon$ & $-\log \left(K_{\mathrm{w}}\right)$ & $\rho$ & $\mu$ \\
\hline $\mathrm{N}_{2}$ & -0.238 & -0.818 & -0.238 & -0.238 \\
& $(0.457)$ & $(0.001)$ & $(0.457)$ & $(0.457)$ \\
$\mathrm{CO}_{2}$ & -0.301 & -0.545 & -0.301 & -0.301 \\
& $(0.342)$ & $(0.067)$ & $(0.342)$ & $(0.342)$
\end{tabular}

yield and $\mathrm{Cu}$ removal percentage are presented in Tables 1 and 2 , respectively.

In each system, $-\log K_{\mathrm{w}}$ demonstrated significant correlation with FA yield regardless of the gas used to pressurize the system. Negative sign of correlation factor between $-\log K_{\mathrm{w}}$ and FA yield indicated that FA yield increased with decreasing $\log K_{\mathrm{w}}$. In other words, FA yield increased with increasing water ionization constant $\left(K_{\mathrm{w}}\right)$. This signifies the important role of water as the medium for generation and transfer of free proton $\left(\mathrm{H}_{3} \mathrm{O}^{+}\right)$in the catalyst system. With sufficient capacity of proton generation, autocatalytic as well as acid catalytic mechanisms were enhanced dramatically. In Cu-catalyzed system, increasing ionization constant facilitated production of FA, which promoted $\mathrm{Cu}$ soap formation. That relationship was also observed specifically in Table 1 . Meanwhile, negative signs of the other correlation factors of remaining SCW properties denoted better reaction performance by means of better miscibility and mixing properties between water and oil with lower $\varepsilon, \mu$, and $\rho$. From this strong correlation and the dynamic portrait of SCW properties change in Fig. S6, $\uparrow$ the main and interaction effect of temperature and additional pressure towards FA yield and $\mathrm{Cu}$ removal become much clearer. A surge in the mean value of FA yield and $\mathrm{Cu}$ removal (Fig. 1) can be explained by a large decreasing of $-\log K_{\mathrm{w}}$ from 200 to $225{ }^{\circ} \mathrm{C}$. Since $-\log K_{\mathrm{w}}$ reduction was also caused by the rising of added pressure, the significance of added pressure in affecting $\mathrm{Cu}$ removal is also reasonable. Although the correlation values for $\varepsilon, \mu$, and $\rho$ were not as significant as the $-\log \left(K_{\mathrm{w}}\right)$, it is still important to realize that without good mixing and miscibility of water and oil, the catalysis mechanism might fail to take strong effect on the oil hydrolysis reaction.
Substitution of $\mathrm{N}_{2}$ by $\mathrm{CO}_{2}$ showed alteration of correlation factors, especially for the autocatalytic system, where $\varepsilon, \rho$, and $\mu$ became significant in effect. Although remained significant, the same phenomena also occurred in the acid-catalyzed and $\mathrm{Cu}$ catalyzed systems. This can be described as the effect of oil dilution by $\mathrm{CO}_{2}$ that eventually revealed the role of mixing properties of SCW in FA production, which explained why mean FA yield was only slightly lowered despite of dilution (Fig. 1). Under $\mathrm{N}_{2}$ pressure or no dilution effect, SCW properties were approximately similar (Fig. S6 $\dagger$ ) since the temperatures and actual pressures were very close to those using $\mathrm{CO}_{2}$, but the effect of those properties became less appreciated since no hindrance existed for the excess liquid SCW to reach oil molecules.

$\mathrm{Cu}$ removal percentage was influenced by water ionization constant (Table 2) that implies water activity to form more FA during $\mathrm{Cu}$ soap formation. In the presence of $\mathrm{CO}_{2}$, the influence of water ionization constant became insignificant ( $p$-value $>\alpha=$ $0.05)$, but statistically made some difference ( $p$-value $<\alpha=0.1$ ). One plausible reason for this change is enhanced dilution of FA by $\mathrm{CO}_{2}$ that inhibited $\mathrm{Cu}$ formation. The other properties associated with mixing and miscibility of oil and aqueous phase (i.e., $\varepsilon, \mu$, and $\rho$ ) did not correlate significantly with $\mathrm{Cu}$ removal. This can be described as the weakness using the correlation analysis. Since the data majority indicated sufficiently low polarity that allowed remarkable amount of FA to dissolve easily in the water without certain degree of mixing, the effect of $\varepsilon, \mu$, and $\rho$ were showed to be insignificant. When the data analysis was reduced to contain only the data with remarkable change of SCW properties, especially on the $\varepsilon, \mu$, and $\rho$, the correlation analysis resulted into very high correlation between SCW properties and FA yield (all correlation factors are -1.000 with $p$-values $<0.000)$. This also occurred for the correlation between $\mathrm{SCW}$ properties and $\mathrm{Cu}$ removal.

\subsection{Relation between operating parameters, SCW properties, and catalysis mechanism}

Reaction medium affects catalysis mechanism. The role of water as reaction medium and reactant is greatly influenced by its dielectric constant $(\varepsilon)$ and ionic product $\left(-\log K_{\mathrm{w}}\right)$, while water density $(\rho)$ and viscosity $(\mu)$ only affect the mixing behavior. ${ }^{3}$ In this study, $\mathrm{Cu}$ soap formation and oil hydrolysis reaction were found to be significantly influenced by the decrease of $-\log K_{\mathrm{w}}$ along with three explicit catalysis mechanisms: strong Bronsted acid catalysis of $\mathrm{H}_{2} \mathrm{SO}_{4}$, Lewis acid catalysis of $\mathrm{Cu}$ soap, and weak Bronsted acid catalysis of FFA. Comprehension on the interrelationship between temperature as the most significant operating parameter that drastically affected $-\log K_{\mathrm{w}}$ and $\varepsilon$ with SCW properties and the mechanism of the hydrolysis reaction with the involving catalysis mechanism may contribute better insight on the reaction in SCW.

The effect of $-\log K_{\mathrm{w}}$ can be well explained from its influence on the acid deprotonation with respective proton balance mathematical relationships for strong and weak Bronsted acid as follows: ${ }^{33}$ 


$$
\begin{gathered}
{\left[\mathrm{H}_{3} \mathrm{O}^{+}\right]=\frac{C_{\mathrm{A}}+\sqrt{C_{\mathrm{A}}+4 \times K_{\mathrm{w}}}}{2}} \\
{\left[\mathrm{H}_{3} \mathrm{O}^{+}\right]=\frac{-K_{\mathrm{A}}+\sqrt{K_{\mathrm{A}}^{2}+4 \times K_{\mathrm{A}} C_{A}}}{2}}
\end{gathered}
$$

where $\left[\mathrm{H}_{3} \mathrm{O}^{+}\right]$is the concentration of the liberated proton, while $C_{\mathrm{A}}$ and $K_{\mathrm{A}}$ are the acid concentration and weak acid dissociation constant, respectively. From these equations, it is clear that $-\log K_{\mathrm{w}}$ only affects the strong Bronsted acid catalysis mechanism, where the ionized water molecules exponentially increases the concentration of proton in the system in addition to the protons from strong acid ionization. The existence of $\mathrm{OH}^{-}$from water dissociation indeed counterbalances the amount of $\mathrm{H}_{3} \mathrm{O}^{+}$from water, but $\mathrm{OH}^{-}$also can trigger more complete deprotonation of polyprotic acids, which produces another water molecule by acid-base reaction. Although described in a different way, the effect of $\mathrm{OH}^{-}$from water ionization is quite similar with the ability of water to receive more proton in addition to the uniformly distribute around the structure of polyprotic acid (i.e., $\mathrm{H}_{2} \mathrm{SO}_{4}$ in this studied system) to construct stable molecular conformation of completely deprotonated structure. ${ }^{34}$

On the other hand, $-\log K_{\mathrm{w}}$ surprisingly does not govern FA deprotonation that influences weak Bronsted acid catalysis and $\mathrm{Cu}$ soap formation as explicitly described in the relationship between water and weak acid ionization $\left(K_{\mathrm{w}}=K_{\mathrm{A}} \times K_{\mathrm{B}}\right)$. Based on this, the autocatalysis by FFA in the SCW-oil hydrolysis reaction should be re-assessed. Regarding FFA autocatalytic ability, it is possible that FA dissociation was enhanced by the manipulation of reaction conditions. However, according to previous studies, FA dissociation decreased with increasing temperature and the drop in dielectric constant of the medium. ${ }^{35,36}$ Thus, the behavior of FA in the reaction condition applied in this study can be predicted to be less prone to dissociation, resulting in less production of free proton as catalyst. Consequently, autocatalysis is not the dominating mechanism in this system though autocatalysis of FA is still quite valid since the dissociation is not nullified. In line with the correlation analysis, the active catalysis in the autocatalyzed system is more likely to be the auto-generation of proton from water molecules, while the $\mathrm{OH}^{-}$produced might randomly react with FAs to produce another water molecule without interrupting the positive net balance of proton generation. This indication also proves the difference made by dielectric constant $(\varepsilon)$ in FA production (Table $1 ; 0.05<p$-value $<$ 0.1 ) that improved water penetration into oil phase to catalyze the reaction. Moreover, this minute net generation of the protons from FAs and water molecules may explain why FA yield of auto-catalyzed system was remarkably small compared to catalyzed systems.

The involvement of SCW in Cu-catalyzed system is more complicated since $\mathrm{Cu}$ soap formation was included. By considering the decrease in FAs deprotonation occurred in the applied conditions, it can be deduced that more formation and solubility of FAs promoted $\mathrm{Cu}$ soap formation by means of ion exchange reaction. This can be done with the help of proton from water ionization on the hydrolysis of acylglycerides as reflected in the significance of $-\log \left(K_{\mathrm{w}}\right)$ and low polarity (low $\varepsilon$ ) environment that can enhance FAs solubility in the water phase, which took place at high water temperature. ${ }^{37}$ Complexation between $\mathrm{Cu}^{2+}$ and FAs was very unlikely to occur since the stability complex of Cu-FAs is declining at higher temperature. ${ }^{36}$ The other possible mechanism is the alkalinization of $\mathrm{Cu}^{2+}$ by $\mathrm{OH}^{-}$generated from water dissociation, which rendered to more reaction with the FAs with more self-ionization of water. ${ }^{38}$ The alkalinization of $\mathrm{Cu}^{2+}$ is also known as the result of $\mathrm{Cu}^{2+}$ hydrolysis. Coincidentally, the $\mathrm{Cu}^{2+}$ hydrolysis exhibited endothermic nature $\left(\Delta H^{0}=17.5 \pm 2 \mathrm{kcal} \mathrm{mol}^{-1}\right)$ with positive entropy $\left(\Delta S^{0}=11.4 \pm 7 \mathrm{cal} \mathrm{mol}^{-1} \mathrm{~K}^{-1}\right)$, which also supports the proposed mechanism of $\mathrm{Cu}^{2+}$ alkalinization with the ionized water at elevated temperature. ${ }^{39}$

As $\mathrm{Cu}$ soap formed entered into oil phase, further reaction with water as electron donor proceeded. In this step, the role of $\mathrm{Cu}$ soap as Lewis acid that produced free proton from water was strengthened with higher water ionization constant. In addition, water ionization might be involved in acid catalysis of $\mathrm{H}_{2} \mathrm{SO}_{4}$ formed as the by-product of $\mathrm{Cu}$ soap formation by means of cation exchange between $\mathrm{CuSO}_{4}$ and FAs. With both mechanisms worked simultaneously, Cu-catalyzed system could produce more FAs than $\mathrm{H}_{2} \mathrm{SO}_{4}$-catalyzed system as illustrated in Fig. 1.

Based on the elucidated effect of SCW properties on reactions and the relationships of operating parameters and SCW properties in Fig. $66, \uparrow$ the enhancement of $-\log K_{\mathrm{w}}$ was proven to successfully increase the formation rate of FA and $\mathrm{Cu}$ soap, respectively. The ionization behavior of water with the increase of temperature verified the activity of SCW as the combination of reactant and active catalyst in the oil hydrolysis reaction. Low dielectric constant of SCW also improved the solubility of FAs in water, which increased FAs concentration in water. ${ }^{37}$ Low polarity also promoted the formation of non-charged and hydrophobic $\mathrm{Cu}$ soap from $\mathrm{Cu}^{2+}$ and FAs anion in synergy with increasing FAs concentration. ${ }^{33}$ This behavior may explain the negative effect of water at certain amount in transesterification and esterification reactions either in acid-catalyzed system or supercritical methanol system by means of ester hydrolysis. ${ }^{\mathbf{4 0 , 4 1}}$ As described by van't Hoff equation, water ionization is more endothermic than that of methanol $\left(\Delta H^{0}\right.$ at $25{ }^{\circ} \mathrm{C}: 390.8 \mathrm{kcal}$ $\mathrm{mol}^{-1}$ vs. $381.4 \mathrm{kcal} \mathrm{mol}^{-1}$ ) leads to more ionization that results in a higher rate of hydrolysis than ester formation. ${ }^{42}$

\section{Conclusion}

The effect of operating parameters and SCW properties on oil hydrolysis using three different catalyst systems was evaluated. Temperature has more influence on FA production than initial pressure due to its role in enhancing reaction rate in addition to controlling vapor-liquid equilibrium. Substitution of pressurizing gas did not show significant effect on FA yield, but $\mathrm{CO}_{2}$ inhibited $\mathrm{Cu}$ soap formation by primarily diluting the oil and contributing small amount of $\mathrm{H}^{+}$from its deprotonation in water. SCW properties affected catalyst formation through enhancement of catalysis mechanism and mixing properties 
between oil and water. Low polarity and high ion product of SCW influenced the catalysis by increasing the concentration of water-soluble FAs, $\mathrm{Cu}$ soap formation, or better miscibility of proton into oil phase. Water in subcritical state is very active as reactant, medium, and catalysis promoter for oil hydrolysis reaction.

\section{References}

1 V. Mills and H. K. McClain, Ind. Eng. Chem., 1949, 41, 19821985.

2 L. Lascaray, J. Am. Oil Chem. Soc., 1952, 29, 362-366.

3 A. Kruse and E. Dinjus, J. Supercrit. Fluids, 2007, 39, 362-380.

4 H. Luo, K. Xue, W. Fan, C. Li, G. Nan and Z. Li, Ind. Eng. Chem. Res., 2014, 53, 11653-11658.

5 J. Kansedo and K. T. Lee, Chem. Eng. J., 2014, 237, 1-7.

6 E. Minami and S. Saka, Fuel, 2006, 85, 2479-2483.

7 G. C. Gervajio, in Kirk-Othmer Chemical Technology of Cosmetics, ed. A. Seidel, John Wiley \& Sons, New Jersey, 2013, pp. 450-451.

8 N. O. V. Sonntag, J. Am. Oil Chem. Soc., 1979, 56, 729A-732A.

9 N. V. Paranychianakis, M. Salgot, S. A. Snyder and A. N. Angelakis, Crit. Rev. Environ. Sci. Technol., 2015, 45, 1409-1468.

10 M. A. Barakat, Arabian J. Chem., 2011, 4, 361-377.

11 Ihsanullah, A. Abbas, A. M. Al-Amer, T. Laoui, M. J. Al-Marri, M. S. Nasser, M. Khraisheh and M. A. Atieh, Sep. Purif. Technol., 2016, 157, 141-161.

12 M. Kul and K. O. Oskay, Hydrometallurgy, 2015, 155, 153160.

13 M. Al-Shannag, Z. Al-Qodah, K. Bani-Melhem, M. R. Qtaishat and M. Alkasrawi, Chem. Eng. J., 2015, 260, 749-756.

14 J.-C. Lou, Y.-J. Huang and J.-Y. Han, J. Hazard. Mater., 2009, 170, 620-626.

15 L. K. Ong, P. L. T. Nguyen, F. E. Soetaredjo, S. Ismadji and Y.-H. Ju, RSC Adv., 2016, 6, 25359-25367.

16 R. L. Holliday, J. W. King and G. R. List, Ind. Eng. Chem. Res., 1997, 36, 932-935.

17 R. Alenezi, G. A. Leeke, R. C. D. Santos and A. R. Khan, Chem. Eng. Res. Des., 2009, 87, 867-873.

18 A. A. Alexandrov, K. A. Orlov and V. F. Ochkov, Thermophysical Properties of Thermal Power Engineering Working Substances, http://twt.mpei.ac.ru/rbtpp/eng/, accessed 10 April, 2016.

19 J. M. deMan, in Fatty Acids in Foods and their Health Implications, ed. C. K. Chow, CRC Press, USA, 3rd edn, 2008, ch. 2.
20 L.-H. Huynh, N. S. Kasim and Y.-H. Ju, Bioresour. Technol., 2010, 101, 8891-8896.

21 J. R. López-Aguilar, G. Valerio-Alfaro, J. A. Monroy-Rivera, L. A. Medina-Juárez, M. O'Mahony and O. Angulo, Grasas Aceites, 2006, 57, 149-154.

22 M. Canakci, Bioresour. Technol., 2007, 98, 183-190.

23 L. M. Smith, A. J. Clifford, C. L. Hamblin and R. K. Creveling, J. Am. Oil Chem. Soc., 1986, 63, 1017-1023.

24 D. Goburdhun, S. B. Jhaumeer-Laulloo and R. Musruck, Int. J. Food Sci. Nutr., 2001, 52, 31-42.

25 A. D. Leonardis, V. Macciola and M. D. Felice, Int. J. Food Sci. Technol., 2000, 35, 371-375.

26 J.-H. Ryu, S.-Y. Park, S.-Y. Bae and H.-Y. Shin, J. Chem. Eng. Jpn., 2014, 47, 399-405.

27 D. Kusdiana and S. Saka, Appl. Biochem. Biotechnol., 2004, 113-116, 781-791.

28 F. J. Eller, J. A. Teel and D. E. Palmquist, J. Am. Oil Chem. Soc., 2011, 88, 1455-1461.

29 G. Brunner, Hydrothermal and Supercritical Water Processes, Elsevier B.V., Great Britain, 2014.

30 R. B. Gupta and J.-J. Shim, Solubility in supercritical carbon dioxide, CRC Press, USA, 2007.

31 Z. Duan and Z. Zhang, Geochim. Cosmochim. Acta, 2006, 70, 2311-2324.

32 J. M. Prado, D. Lachos-Perez, T. Forster-Carneiro and M. A. Rostagno, Food Bioprod. Process., 2016, 98, 95-123.

33 Martin's Physical Pharmacy and Pharmaceutical Sciences: Physical. Chemical, and Biopharmaceutical Principles in the Pharmaceutical Sciences, ed. P. J. Sinko and Y. Singh, Lippincott Williams and Wilkins, USA, 2011.

34 C.-G. Ding and K. Laasonen, Chem. Phys. Lett., 2004, 390, 307-313.

35 M. A. Rahman, A. K. Ghosh and R. N. Bose, J. Chem. Technol. Biotechnol., 1979, 29, 158-162.

36 A. Gupta, Int. J. Appl. Eng. Res., 2013, 8, 1885-1890.

37 P. Khuwijitjaru, S. Adachi and R. Matsuno, Biosci., Biotechnol., Biochem., 2002, 66, 1723-1726.

38 T. Schneller and D. Griesche, in Chemical Solution Deposition of Functional Oxide Thin Films, ed. T. Schneller, R. Waser, M. Kosec and D. Payne, Springer-Verlag Wien, USA, 2013.

39 C. F. Baes and R. E. Mesmer, The Hydrolysis of Cations, John Wiley \& Sons, Inc., Canada, 1976.

40 D. Kusdiana and S. Saka, Bioresour. Technol., 2004, 91, 289295.

41 Y. Liu, E. Lotero and J. G. G. Jr, J. Mol. Catal. A: Chem., 2006, 245, 132-140.

42 J. Sauer and R. Ahlrichs, J. Chem. Phys., 1990, 93, 2575-2583. 